\title{
LICENCIATURAS NOS INSTITUTOS FEDERAIS: EM BUSCA DE SABERES DOCENTES PARA A EDUCAÇÃO PROFISSIONAL TÉCNICA DE NÍVEL MÉDIO
}

\author{
Fernanda Rebeca Araújo da Silva, Rosa Oliveira Marins Azevedo \\ Instituto Federal do Amazonas \\ Campus Manaus Centro \\ Manaus, Amazonas \\ E-mail: prof.fernandarebeca@hotmail.com, marinsrosa@yahoo.com.br
}

Resumo: Este estudo tem por objetivo investigar quais Saberes Docentes os professores da educação profissional técnica de nível médio mobilizam em sua prática. Entendemos que assim será possível traçar estratégias de ações formativas que contemplem os cursos de Licenciaturas existentes nos Institutos Federais (IF), mais especificamente no IF Amazonas, lócus da pesquisa. Tendo o apoio de teóricos da área elaboramos um percurso metodológico que nos permitisse refletir acerca desta formação, tomando por base a pesquisa-ação, através de observação participante, o que nos proporcionou subsídios à construção de outros momentos formativos. $O$ que nos permitiu visualizar alguns aspectos dos Saberes Docentes para a EPTNM, tais como o conhecimento do mundo do trabalho e o entendimento da formação humana integral.

Palavras-chave: saberes docentes; formação de professores; educação profissional, educação continuada, instituto federal.

\section{COLLEGES FOR TEACHER EDUCATION IN FEDERAL INSTITUTES: IN SEARCH OF KNOWLEDGE TEACHERS FOR PROFESSIONAL EDUCATION TECHNICAL OF MIDDLE LEVEL}

\begin{abstract}
This study aims to investigate which knowledge vocational education teachers teachers mid-level technical mobilize in their practice. We understand that so can strategize the training activities that address the existing undergraduate courses in the Federal Institutes (IF), specifically in IF Amazonas, locus of research. Having the support of theoretical area we developed a methodological approach that would allow us to reflect on this formation, based on action research through participant observation, which provided subsidies for the construction of other formative moments. What allowed us to visualize some aspects of knowledge for teachers EPTNM, such as knowledge of the world of work and an understanding of integral human formation.
\end{abstract}

Keywords: teaching knowledge, teacher training, professional education, federal institute, continuing education.

Recebido em 30/09/2015. Publicado em 30/03/2016. 


\section{INTRODUÇÃO}

Estamos nos dispondo a falar de professores e de seus processos formativos. Mas não são quaisquer professores, tampouco qualquer processo formativo. Este estudo se constrói na necessidade de um momento de discussão, baseado no objetivo de problematizar os saberes necessários à formação de professores para o Ensino Técnico, compreendendo este no bojo da Educação Profissional Técnica de Nível Médio (EPTNM), a qual, por sua vez, perfaz um dos cursos da Educação Profissional e Tecnológica (EPT), de acordo com a Resolução N 6/2008. Neste sentido, comungamos do questionamento de Tardif $(2014$, p. 9), sobre quais são "[...] os conhecimentos, o saber-fazer, as competências e habilidades que os professores mobilizam diariamente" na sua prática.

A partir do conhecimento desses saberes acionados na prática pedagógica podemos pensar em uma concepção de formação para os professores. Notamos ser crucial empreender o diálogo com as questões da profissionalização, encontradas na EPTNM em meio à "ausência de espaços formativos que auxiliem no preparo à docência dos profissionais das áreas propedêuticas e principalmente das áreas técnicas que atuam nestes cursos [EPTNM]". (BAPTAGLIN, 2013, p. 7710, grifo nosso).

Tal questionamento surge da observação da própria instituição que oferece o Mestrado Profissional em Ensino Tecnológico, do qual fazemos parte, no Instituto Federal de Educação Ciência e Tecnologia do Amazonas (IFAM), e que possui, além do ensino técnico e tecnológico, formação de professores para a Educação Básica (anos finais do Ensino Fundamental e Ensino Médio) em Ciências e Matemática.

Ainda que exista um esforço de grupos de estudo e pesquisa ${ }^{1}$ sobre este assunto, que se materializa em publicações que tratam a questão, é inegável o insipiente direcionamento em relação ao ensino e formação professores para a EPTNM que pode resultar num Ensino Técnico dissonante da "[...] perspectiva de formação integral do ser humano e não apenas de sua profissionalização, mediante o desenvolvimento do sujeito em suas múltiplas dimensões, visando

\footnotetext{
${ }^{1}$ Sobretudo os Grupos de Pesquisa de Trabalho e Educação das Pós-Graduações, a exemplo do Grupo de Estudos e Pesquisa sobre Processos Formativos de Professores no Ensino Tecnológico (GEPROFET), do IFAM, certificado pelo $\mathrm{CNPQ}$, que possui um projeto, do qual fazemos parte, centrado na temática.
} 
favorecer sua inserção crítica e criativa não só no trabalho, mas na vida social, cultural e artística". (PONTES, 2014, p. 2). Sendo assim, entendemos haver saberes específicos sobre os quais se constrói a atuação do professor. São estes saberes que pretendemos investigar como necessários à formação docente, bem como os aspectos relacionados a eles.

Dividimos o estudo em quatro momentos, no primeiro, "De Escolas de Aprendizes Artífices às Licenciatura", situamos os marcos históricos e legislativos da EPT até a atualidade, sobretudo acerca da formação de professores; o segundo momento: "Os Saberes Docentes na formação de professores para a Educação Profissional Técnica de Nível Médio" apresentamos o posicionamento epistemológico da investigação; para apresentar o percurso metodológico construído temos a seção "Ações Formativas com os licenciandos: o processo que se faz produto", que nos dará suporte para delinear os resultados e discussões deste processo, que perfaz o quarto momento: "Saberes Docentes para a EPTNM na visão dos licenciandos."

\section{DE ESCOLAS DE APRENDIZES ARTÍFICES ÀS LICENCIATURA}

Educação e trabalho sempre estiveram nas dimensões relacionais dos seres humanos, no embate entre os aspectos econômicos, políticos, culturais e sociais influenciando seus modos de viver e produzir (SILVA; MOURÃO, 2013). Na análise do processo histórico da Educação Profissional no Brasil tais relações se evidenciam considerando as peculiaridades de cada período e como, em cada um deles, a dicotomia entre teoria e prática foram se estabelecendo, sendo uma constante na educação brasileira.

No Brasil, a Educação Profissional (EP) inicia-se dentro de uma perspectiva compensatória e assistencialista (BAPTAGLIN, 2013), com o Decreto 7.566 em 23 de setembro de 1909, assinado pelo presidente Nilo Peçanha, por meio do qual são criadas 19 Escolas de Aprendizes Artífices subordinadas ao Ministério dos Negócios da Agricultura, Indústria e Comércio. (BARATO, 2002, p. 140). Não obstante, as ofertas das instituições de Educação Profissional estavam ligadas às demandas econômicas, representadas pela sua clientela que "era constituída de órfãos e desvalidos", o que as fazia serem vistas mais como "obras de caridade" do que como "obras de instrução pública", possuindo caráter popular. (MANFREDI, 2002, p. 77).

Na República Velha novas configurações econômicas lançam sobre a Educação Profissional um caráter de qualificação para o mercado, sobrepondo-se à perspectiva assistencialista, abrindo-se a 
um novo perfil de aluno: os pertencentes dos setores populares urbanos, futuros trabalhadores assalariados. No decorrer da Era Vargas, as necessidades do mercado em crescente industrialização, em detrimento da produção artesanal, fizeram emergir demandas específicas, que voltam os olhos para a formação profissional numa perspectiva da racionalidade técnicainstrumental, na formação de mão-de-obra.

Após o Estado Novo, alguns marcos legislativos nos ajudam a compreender como se construiu a EP até sua denominação atual como EPT (Educação Profissional e Tecnológica), dos quais destacamos a criação dos Institutos Federais de Educação, Ciência e Tecnologia, mediante a Lei 11892 de 29 de dezembro de 2008. (BRASIL, 2008). A qual passa a abranger formação inicial e continuada para a qualificação profissional; Educação Profissional Técnica de Nível Médio; e Educação Profissional Tecnológica, de graduação e de pós-graduação.

O horizonte que se apresenta hoje é de constante crescimento, de intensificação dos debates dos desafios latentes. Do ponto de vista econômico os investimentos tendem a expandir-se, sob as atuais inovações tecnológicas que inauguraram novos modos de viver e de produzir do século XXI. Nesse contexto surge a necessidade de efetivar uma "educação tecnológica, numa perspectiva de formação de trabalhadores como sujeitos coletivos e históricos". (MANFREDI, 2002, p. 57). Neste ponto, Mancebo (2002, p. 70), afirma:

Na realidade, todo um novo cotidiano vem construindo-se nas universidades, que reflete as transformações por que passa nossa sociedade de forma geral -e, mais especificamente, as que foram introduzidas no mundo do trabalho -, modificações carreadas pelo avanço das tecnologias da informação e pelo processo mais geral de mundialização do capital e do papel estratégico que a produção de conhecimento desempenha nesse processo. Assim, o trabalho docente e sua produção - ou sua produtividade - ganham um novo caráter, que precisa ser cuidadosamente analisado.

Essa afirmação dialoga com Moura (2008), fazendo-nos pensar em formação de professores que considerem todas essas modificações ditadas pela flexibilidade, volatilidade e efemeridade do mercado e das relações sociais, sem, contudo, fechar-se na esfera mercadológica, exigindo uma formação para além da força de trabalho, resgatando subjetividade e formação humana. 
Retomando a questão histórica, anterior à criação dos IFs, temos que na formação de professores, “prevalecia a tradição pragmática de acolher professores sem formação, a partir do pressuposto de que não havia necessidade de nenhum método pedagógico específico". (Aranha, 2006, p. 227). Devido, em parte, a instabilidade histórica a formação de seus professores da EPT ficou marcada por uma "política de não formação", "sendo tratada, no país como algo especial, emergencial, sem integralidade própria e viabilizando propostas de formação aligeirada e superficial, que carece de marco regulatório" (GARÍGLIO e BURNIER, 2012, p. 213).

Nos deparamos então, com a herança de um insipiente direcionamento quanto a formação de professores para a EPT. No entanto, este trabalho tem uma temática mais específica, referente à Educação Profissional Técnica de Nível Médio, e sua relação com as Licenciaturas. Dentro da legislação, vemos que a EPTNM está dentro da Educação Profissional e Tecnológica, como um de seus cursos. (BRASIL, 2012). Além disso, existe um intercruzamento entre a EPTNM e a Educação Básica, no Ensino Médio, conforme representado na Figura 1.

Figura 1: A EPTNM no contexto da EPT.

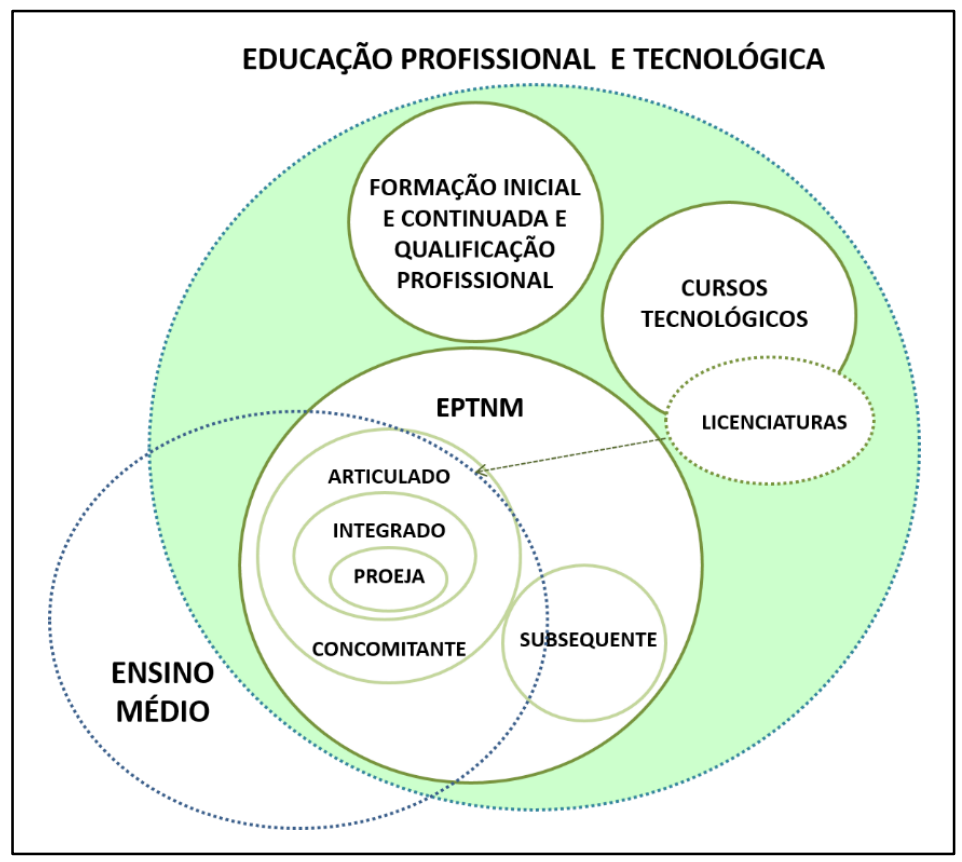

Fonte: Dados da investigação.

As Licenciaturas, conforme trazidas acima, dizem respeito àquelas que são ofertadas nos Institutos Federais, historicamente consolidados como instituições de Educação Profissional e Tecnológica. O fato de estarem inseridas neste contexto nos faz indagar: qual o sentido desses cursos na 
trajetória dessas instituições? A resposta vem de um quadro maior, relacionada a uma necessidade primária da educação: professores.

Diante de um déficit de mais de 235 mil professores, principalmente nas disciplinas de Física, Matemática, Química e Biologia (BRASIL, 2008b), a Lei no 11.892, no seu artigo 7o, aponta que uma das finalidades dos Institutos Federais passou a ser ofertar "cursos de licenciatura, bem como programas especiais de formação pedagógica, com vistas na formação de professores para a educação básica, sobretudo nas áreas de ciências e matemática e educação profissional“.

Esta última possibilidade deve-se às características estruturais dos Institutos Federais em termos de verticalização do ensino, uma vez que, no mesmo espaço, há uma diversidade de modalidades que tem como fio condutor a Educação Profissional. Essas instituições oferecem desde a Educação Básica, com o Ensino Médio articulado e subsequente; Ensino Superior, com Engenharias, cursos Tecnológicos e Licenciaturas; até a Pós-graduação lato sensu e scricto sensu. Esta estrutura peculiar dos IFS representa aos futuros professores

[...] um espaço ímpar de construção de saberes, por terem a possibilidade de, no mesmo espaço institucional, construir vínculos em diferentes níveis e modalidades de ensino; em diferentes níveis da formação profissional, assim como buscar metodologias que melhor se apliquem a cada ação, estabelecendo a indissociabilidade entre ensino, pesquisa e extensão. (MEC, 2010, p. 27).

De 2008 a 2014, observou-se um investimento sem precedentes no Ensino Profissional e Tecnológico, sobretudo na expansão da Rede Federal de Educação Profissional, Científica e Tecnológica, mediante a Lei 11.892. (BRASIL, 2008b). Baptaglin (2012, p.7710) apresenta as instituições que compõe esta Rede:

Escolas Técnicas e Agrotécnicas Federais, Escolas Técnicas vinculadas às Universidades (25 Escolas Técnicas), Centros Federais de Educação Tecnológica (2 CEFET), Institutos Federal de Educação, Ciência e Tecnologia (38 IFET e 356 Campi) e a Universidade Tecnológica Federal do Paraná.

Diante do aumento de vagas nessas instituições, 50\% são destinadas a Educação Técnica de Nível Médio, com o Ensino Médio Integrado, e 20\% para Licenciaturas. (BRASIL, 2008b). De acordo com isso, o objetivo dos IF passou a ser formar professores tanto para a Educação Básica como para a 
Educação Profissional, sobretudo a EPTNM, pois ela conjuga estas duas modalidades e etapas da educação.

Em nossa investigação, iremos privilegiar a construção de Saberes Docentes para a EPTNM em sua forma articulada/integrada, também denominado como Ensino Médio Integrado (EMI). Isso porque, nesta forma de oferta, há a possibilidade de diálogo maior entre os professores das áreas técnicas e os professores de formação geral, por estarem na mesma instituição sob os mesmos projetos de cursos. E está em consonância com a formação dos sujeitos da pesquisa, a saber, Educação Profissional e Educação Básica. Tal diálogo está contido na proposta do EMI, o qual se pauta, conforme Pontes (2014, p. 2), “[...] numa perspectiva de formação integral do ser humano e não apenas de sua profissionalização, mediante o desenvolvimento do sujeito em suas múltiplas dimensões, visando favorecer sua inserção crítica e criativa não só no trabalho, mas na vida social, cultural e artística".

Consonante a intencionalidade do EMI é possível perceber que não se trata de uma simples conjugação entre o aspecto técnico e os aspectos gerais da formação dos jovens, mas na integração entre eles, superando alguma dualidade que se interponha entre estes dois aspectos. Isto quer dizer que atuar nesse campo demanda e mobiliza saberes específicos, o que requer a necessidade de problematizar tal ensino, desde a formação inicial, despontando os IF.

Diante das possibilidades ${ }^{2}$ para discutir a formação de professores neste âmbito, tomamos como posicionamento a tendência dos Saberes Docentes, cujo expoente no Brasil é Maurice Tardif. A escolha se deu tanto pelo caminho traçado por outros pesquisadores, como pelo fato desta tendência discutir sobre a profissionalização dos professores, o que se mostra insipiente, especialmente na Educação Profissional e Tecnológica. (GARÍGLIO; BURNIER, 2012).

\section{OS SABERES DOCENTES NA FORMAÇÃO DE PROFESSORES PARA A EDUCAÇÃO PROFISSIONAL TÉCNICA DE NÍVEL MÉDIO}

\footnotetext{
${ }^{2}$ Quando se trata de formação de professores no Brasil, pelo menos quatro tendências se evidenciam advindas também do diálogo internacional com diversos teóricos acerca do tema. Tais tendências são: os Saberes Docentes, o professor Reflexivo, o professor Pesquisador, as Competências. Ou, no dizer de Ghedin: "saber docente, reflexão sobre a prática, pesquisa no ensino e competências da formação" (2009, p. 4).
} 
O posicionamento epistemológico adotado na pesquisa repousa sobre a concepção de Saberes Docentes sob a ótica proposta por Maurice Tardif, em meados da década de 80, quando começa a se discutir a profissionalização do ofício de professor a partir do reconhecimento de Saberes Docentes específicos e mobilizados na sua atuação. Tardif tornou-se um expoente nesse campo, sobretudo no Brasil, na década de 90, gerando o movimento de compreender (e de assumir) a complexidade da prática pedagógica, no entanto, a grande repercussão, se deu em 2002, com o lançamento da obra "Os Saberes Docentes e Formação Profissional", já em sua 16a edição, em 2014.

Antes da década de 80 , as pesquisas educacionais, bem como o entendimento geral da sociedade acerca dos rumos da educação, residiam em aspectos exteriores à escola. Pouco se atribuía o sucesso ou insucesso da educação à atuação do professor, como tendo um papel decisivo nos processos (CARDOSO, DEL PINO e DORNELES, 2012). Guathier et al. (2006) sugere que esse ocultamento da figura do professor se dê pelo fato de não se reconhecerem os saberes específicos inerentes à docência, conferindo, por conseguinte, uma visão "desprofissionalizada" da mesma.

De acordo com Tardif (2014), a proposta de formação que considera os Saberes Docentes é uma resposta crítica aos enfoques anglo-americanos que marcam supremamente os aspectos psicológicos dos professores, e à abordagem europeia tecnicista fomentada pelas vias das competências e, ao mesmo tempo, um questionamento da visão sociológica dos professores como meros reprodutores de uma ordem posta de dominação, na manutenção de um status quo.

$\mathrm{Na}$ contramão de uma explicação simplista da docência como sacerdócio, subordinado a uma vocação, os estudos fizeram parte de um movimento para a profissionalização da atividade docente (CARDOSO, DEL PINO e DORNELES, 2012). O que foi evidente ao longo da história da EPT e da formação de seus professores, em uma "política de não formação". Sendo assim, discutir os saberes acionados na EPTNM, lançam bases para uma concepção de formação.

Sobre essa questão é importante lembrar que as pesquisas sobre a formação de professores têm forte referência na questão da profissionalização do ensino e do magistério, no esforço dos pesquisadores em definir a natureza dos conhecimentos profissionais que serviriam de base ao exercício da docência. Essa definição ajudaria os governos a projetar padrões curriculares nacionais para a 
formação de professores, assim como metas a serem alcançadas pelos centros de formação inicial e continuada. (GARÍGLIO e BURNIER, 2012, p. 216).

Em sua obra Tardif relaciona os saberes docentes com a formação profissional e o exercício da docência. Em nosso estudo, consideramos a formação inicial de professores como a continuação de um diálogo entre os saberes, que perpassa as vivências do professor como pessoa e profissional.

O autor procurou elencar os saberes que são mobilizados pelos professores em sua prática, e os considerou como sendo construídas no percurso de vida dos docentes, em suas experiências, as mais diversas. O saber profissional dos professores, de acordo com o autor é "um amálgama de diferentes saberes, provenientes de fontes diversas, que são construídos, relacionados e mobilizados pelos professores de acordo com as exigências de sua atividade profissional. " (CARDOSO; DEL PINO e DORNELES, 2012, p. 4).

O que podemos compreender é que esses saberes profissionais, nem sempre são oriundos de espaços eminentemente profissionais, mas juntos, acabam por guiar o professor enquanto profissional. E pelo menos três movimentos colocam os professores como geradores de saberes: o movimento de construir, mobilizar e relacionar, estes saberes entre si, e consigo mesmos. Todo esse movimento é gerido de acordo com as "exigências de sua atividade profissional", isto quer dizer que os saberes docentes estão relacionados às demandas de determinado contexto educacional, mobilizando saberes diversos de acordo com estes contextos. Revela-se assim, a existência de Saberes Docentes em um dado tempo e lugar, entre modalidades e níveis do sistema escolar, como no caso de nosso estudo, a Educação Profissional Técnica de Nível Médio.

A partir de pesquisas com os professores, Tardif entende que os saberes docentes são plurais, pois são oriundos de diversas fontes, como já dissemos, podendo ser classificados a partir destas. A esse respeito,

[...] uma classificação coerente dos saberes docentes só existe quando associada à natureza diversa de suas origens, às diferentes fontes de sua aquisição e as relações que os professores estabelecem entre os seus saberes e com os seus saberes. (CARDOSO; DEL PINO; DORNELES, 2012, p. 2). 
Antes de continuarmos na implicação dessa tendência à EPTNM, cabe a nós situar o que se entende por Saberes Docentes. Considera-se que estes sejam os elementos que constituem a prática do professor. Sendo um saber social, é diferente de conhecimento científico, tampouco está regido pela mera vivência, se assim fosse poderíamos considerar como saber docente todas as vivências e sentimentos dos professores, o que abriria espaço para o "excesso etnográfico". Embora os saberes docentes englobem os conhecimentos, as competências, as habilidades (ou aptidões) e as atitudes, isto é, o saber, saber-fazer, saber-ser; não podemos considerar crenças, ideologias e ideias pré-concebidas como saberes docentes (GARÍGLIO e BURNIER, 2012).

Este posicionamento de Tardif explica-se por sua concepção da relação teoria e prática. Para ele, o saber não se constrói fora da prática, sendo assim o saber está ao lado da teoria, isto é, uma prática despojada de saber é constituída por um pretenso saber, que se revela, como já dito, em ideias pré-concebidas, ideologias e crenças. Para ele, o saber docente reside na argumentação. (GARÍGLIO e BURNIER, 2012).

Dentro desse posicionamento o professor seria um ator social racional, imerso em um habitus ${ }^{3}$ e capital cultural ${ }^{4}$. "Pode-se dizer que os professores estão integrados num ambiente sócio profissional que determina, de antemão, certas exigências de racionalidade no interior dos quais o trabalho docente encontra-se preso, estruturado, condicionado". (TARDIF, 2014, p. 205).

A abordagem proposta por Tardif situa "o saber do professor na interface entre o individual e o social, entre o ator e o sistema, a fim de captar a sua natureza social e individual como um todo" (TARDIF, 2014, p. 16). No entanto, alerta para as diversas distorções que têm sido feitas nas pesquisas que pretensamente se dizem alocar na tendência dos saberes docentes. Por esta razão,

\footnotetext{
${ }^{3} \mathrm{O}$ conceito de habitus possui uma história dentro das ciências humanas, no entanto, o recorte aqui feito, remete a Pierre Bourdieu. Segundo ele, é "um conceito capaz de conciliar a oposição aparente entre realidade exterior e as realidades individuais, [...] um sistema de esquemas individuais, socialmente construído de disposições estruturadas (no social) e estruturantes (nas mentes), adquirido nas e pelas experiências práticas (em condições sociais específicas de existência), constantemente orientado para funções e ações do agir cotidiano" (SETTON, 2002, p.63). É uma subjetividade em socialização.

${ }^{4}$ Capital cultural é um termo igualmente sistematizado por Pierre Bourdieu. Para ele, o espaço social é um espaço de lutas, por esta razão estruturas simbólicas como a cultura são importantes na compreensão da dinâmica social. Na diferenciação entre grupos dominantes, e outras minorias, a cultura se torna elemento de dominação quando se entende que uma é superior à outra. Na escola, cada pessoa nos grupos traz consigo uma bagagem cultural cabe à escola compreender esses meandros a fim de valorizar as diferenças e não perpetuar a violência simbólica possível de ser tacitamente instaurada. (CUNHA, 2007).
} 
ele indica que sua abordagem possui seis fios condutores, que iremos apresentar de forma sintetizada.

Primeiro, os saberes docentes estão intimamente ligados ao trabalho, ao locus de atuação do professor. Neste sentido o saber não é um instrumento para o uso do trabalho, mas produzido e modelado por ele. Segundo, esse saber é plural, múltiplo e advêm de momentos e lugares diferentes: da sociedade, escola, cursos de formação, etc. O terceiro, intimamente ligado ao segundo, diz respeito à temporalidade do saber, nas histórias de vida dos docentes. "Dizer que o saber dos professores é temporal significa dizer, inicialmente, que ensinar supõe aprender a ensinar, ou seja, aprender a dominar progressivamente os saberes necessários à realização docente" (TARDIF, 2014, p. 20). O quarto sinaliza que a própria experiência do professor, no seu fazer da prática diária o ensina a ensinar, agregando aos seus saberes enquanto docente. E é nesse fazer, o quinto fio condutor se entrelaça, o qual preconiza o trabalho do professor como interativo. Isto quer dizer que a interação com os alunos e demais pessoas no âmbito educacional, reveste-se de caráter formativo ao docente.

De acordo com Cardoso, Del Pino e Dorneles (2012), podemos classificar os saberes docentes em associações:

1) natureza das suas diversas origens;

2) diferentes fontes de sua aquisição;

3. relações que os professores fazem entre os seus saberes; e

4. relações que os professores fazem eles mesmos com os seus saberes.

Todos esses aspectos envolvidos põem-nos diante do desafio de dialogar com os licenciandos acerca de sua formação, considerando-a em sua complexidade. Para Tardif (2014), os saberes docentes são plurais, tecido por fatores e contextos que o autor enumera em cinco. Para sintetizálos, vamos nos utilizar de um esquema apresentado na Figura 5.

Quadro 1. Dos fatores pelos quais se desenvolvem os Saberes Docentes.

\begin{tabular}{|l|l|l|}
\hline \multicolumn{2}{|c|}{$\begin{array}{c}\text { SABERES DOS } \\
\text { PROFESSORES }\end{array}$} & \multicolumn{1}{c|}{$\begin{array}{c}\text { MODOS DE INTEGRAÇÃO NO } \\
\text { TRABALHO DOCENTE }\end{array}$} \\
\hline $\begin{array}{l}\text { Saberes Pessoais dos } \\
\text { Professores }\end{array}$ & $\begin{array}{l}\text { A família, o ambiente de vida, a } \\
\text { educação no sentido lato, etc. }\end{array}$ & $\begin{array}{l}\text { Pela história de vida e pela } \\
\text { socialização primária. }\end{array}$ \\
\hline
\end{tabular}




\begin{tabular}{|c|c|c|}
\hline $\begin{array}{l}\text { Saberes provenientes da } \\
\text { formação escolar anterior }\end{array}$ & $\begin{array}{l}\text { A escola primária e secundária, os } \\
\text { estudos, pós-secundários não } \\
\text { especializados, etc. }\end{array}$ & $\begin{array}{l}\text { Pela formação e pela socialização } \\
\text { pré-profissionais. }\end{array}$ \\
\hline $\begin{array}{l}\text { Saberes provenientes da } \\
\text { formação profissional para o } \\
\text { magistério }\end{array}$ & $\begin{array}{l}\text { Os estabelecimentos de formação de } \\
\text { professores, os estágios, os cursos de } \\
\text { reciclagem, etc. }\end{array}$ & $\begin{array}{l}\text { Pela formação e pela socialização } \\
\text { profissionais nas instituições de } \\
\text { formação de professores. }\end{array}$ \\
\hline $\begin{array}{l}\text { Saberes provenientes dos } \\
\text { programas e livros didáticos } \\
\text { usados no trabalho }\end{array}$ & $\begin{array}{l}\text { A utilização das "ferramentas" dos } \\
\text { professores: programas, livros didáticos, } \\
\text { cadernos de exercícios, fichas, etc. }\end{array}$ & $\begin{array}{l}\text { Pela utilização das "ferramentas" } \\
\text { de trabalho, sua adaptação, às } \\
\text { tarefas. }\end{array}$ \\
\hline $\begin{array}{l}\text { Saberes provenientes de sua } \\
\text { própria experiência na } \\
\text { profissão, na sala de aula e } \\
\text { na escola. }\end{array}$ & $\begin{array}{l}\text { A prática do ofício na escola e na sala de } \\
\text { aula, a experiência dos pares, etc. }\end{array}$ & $\begin{array}{l}\text { Pela prática do trabalho e pela } \\
\text { socialização profissional. }\end{array}$ \\
\hline
\end{tabular}

Fonte: Tardif (2014, p. 63).

Até aqui, vimos os seis fios condutores, as associações entre os saberes e as suas fontes e contextos. Mas afinal? Quais seriam os Saberes Docentes postulados por Tardif? O seu modelo tipológico compreende quatro Saberes: 1. Da "formação profissional", cuja fonte e disseminação são nos momentos de formação inicial e/ou continuada dos professores; diz respeito às ciências e erudição, dos saberes pedagógicos (saber-fazer), do ponto de vista procedimental, mas também na vivência com os professores, nos seus modos de ser e estar, na perspectiva atitudinal; sendo estes transmitidos também cientificamente, de maneira conceitual. 2. "Saberes disciplinares". Sendo disseminados pelas instituições escolares, dizem respeito à aprendizagem dos conhecimentos científicos construídos e acumulados pela humanidade, apresentando-se em grandes áreas, como exatas, ciências da natureza e humanidades. 3. Os "saberes curriculares", por sua vez, relacionam estes conhecimentos científicos ao ensino e realidade escolar, a fim de que sejam "ensináveis", disseminados através das instituições escolares em programas, projetos políticos pedagógicos, e do currículo em geral. 4. Os "saberes experienciais" são aqueles que advêm "do chão da escola", nas vivências, experiências e interações dos professores com os alunos e colegas.

É importante reiterar que cada uma dessas fontes (Figura 2) e Saberes (Figura 3) são pertencentes a um constructo, que não se descola dos aspectos históricos, contextuais, e das tendências formativas que se apresentam em determinados períodos e contextos. Como vimos no decorrer 
da história da EPT em seus variados contextos, os saberes demandados dos professores se modificam, conforme a conjuntura de sua época, indicando que falar em Saberes Docentes implica em considerá-los como construções em constante feitura, oriundas de processo dialógico que se faz no tempo e no trabalho.

[...] toda práxis social é de uma certa maneira, um trabalho cujo processo de realização desencadeia uma transformação real no trabalhador, [...]. Em termos sociológicos, pode-se dizer que o trabalho modifica a identidade do trabalhador, pois trabalhar não é somente fazer alguma coisa, mas fazer alguma coisa de si mesmo, consigo mesmo. (TARDIF e RAYMOND, 2000).

Isto quer dizer o ser professor está intimamente relacionado com o seu fazer, na medida em que ao mesmo tempo em que interfere sobre ele, é transformado pela prática. Por esta razão, dentro da pluralidade dos saberes docentes, aqueles oriundos da experiência são nos quais os professores possuem maior legitimidade, por serem situados e oriundos do próprio ensino.

Pensando nisso, a priori, os sujeitos da pesquisa seriam apenas licenciandos em contato com o trabalho (e em trabalho) docente, por meio do estágio, e Pibid ${ }^{5}$, pois pensamos que somente assim seria possível observar em totalidade a interação dos saberes docentes colocados por Tardif. No entanto, no decorrer da caminhada, não apenas tais alunos, mas outros, os quais não tinham contato com a sala de aula na EPTNM uniram-se ao caminho que estava sendo traçado. Compreendendo o que está posto na Figura 1, tais alunos teriam condições de inferir sobre a formação para a EPTNM, por estarem em contato, mesmo que (in)diretamente com ela.

\section{AÇÕES FORMATIVAS COM OS LICENCIANDOS: O PROCESSO QUE SE FAZ PRODUTO}

Considerando o objeto de estudo, podemos alocar a pesquisa, por sua natureza, como qualitativa e como estratégia metodológica, a pesquisa-ação, o que implica em uma interferência transformadora na realidade/sujeitos pesquisados. A pesquisa qualitativa em nossa pesquisa é relevante porque considera que há uma relação dinâmica entre o mundo real e o sujeito, isto é, um vínculo indissociável entre o mundo objetivo e a subjetividade do sujeito que não pode ser traduzida em números, sendo uma atividade sistemática orientada à compreensão em

\footnotetext{
${ }^{5}$ Programa Institucional de Bolsas de Iniciação à Docência.
} 
profundidade de fenômenos educativos e sociais, à transformação de práticas e cenários socioeducativos, à tomada de decisões e também ao descobrimento e desenvolvimento de um corpo organizado de conhecimentos (ESTEBAN, 2010, p. 127).

Juntamente com a implementação da pesquisa-ação como estratégia de pesquisa, os seguintes procedimentos serão adotados: 1) Observação participante com os estudantes das licenciaturas na disciplina Seminário de Estágio e nas reuniões do PIBID 2) prévia elaboração de uma proposta de intervenção a partir dos momentos de observação. A partir disso, os passos posteriores são a aplicação de questionário e rodas de conversas no aprofundamento de alguns aspectos a fim de conhecer as perspectivas dos sujeitos acerca dos saberes docentes necessários à atuação no ensino técnico.

Posto isso, procuramos investigar a construção de Saberes para o Ensino Técnico nos cursos de Ciências (Biologia, Química e Física) junto aos alunos que estão em contato com a sala de aula de Ensino Médio Integrado ao Técnico, por meio do estágio supervisionado, e do Programa Institucional de Bolsas de Iniciação à Docência $(\text { Pibid })^{6}$, no âmbito do IFAM. Através desses momentos com os alunos, estes puderam expressar suas inquietações, problemáticas e vivências nesse contexto, dos quais buscamos consideramos os saberes mobilizados na prática docente.

Para tal, foi elaborado um processo metodológico pautado na pesquisa-ação (TRIPP, 2005). Barbier (2007, p. 51), afirma que neste tipo de pesquisa, o objeto emerge durante o processo: “Ora, é somente durante o processo de pesquisa que o verdadeiro objeto (a necessidade, o pedido, os problemas) emerge, e que os participantes são capazes de apreendê-lo."

A pesquisa-ação reconhece que o problema nasce, num contexto preciso, de um grupo em crise. O pesquisador não o provoca, mas constata-o, e seu papel consiste em ajudar a coletividade a determinar todos os detalhes mais cruciais ligados ao problema numa ação coletiva (p. 54).

Desse ponto de vista o objeto não é mais "propriedade" do pesquisador e seu orientador, os sujeitos passam a comungar da mesma busca, mediatizados pelo mesmo objeto, inferindo sobre

\footnotetext{
6 “O Pibid é uma iniciativa para o aperfeiçoamento e a valorização da formação de professores para a educação básica. [...] Os projetos devem promover a inserção dos estudantes no contexto das escolas públicas desde o início da sua formação acadêmica para que desenvolvam atividades didático-pedagógicas sob orientação de um docente da licenciatura e de um professor da escola" (Capes, 2015).
} 
ele e se perguntando a(s) mesma(s) pergunta(s), por exemplo: o que é necessário ao docente da EPTNM, e como os cursos de licenciatura estão contribuindo para isso? De que(ais) forma(as) é possível fazê-lo?

Neste ponto, a postura do pesquisador modifica-se, alinhado com a pesquisa qualitativa, temos um pesquisador que entra no processo e interage com os sujeitos, até tornar-se, de certa forma, ele mesmo um sujeito da pesquisa: "A pesquisa-ação obriga o pesquisador de implicar-se. Ele percebe como está implicado pela estrutura social na qual ele está inserido e pelo jogo de desejos e de interesses de outros. Ele também implica os outros por meio do seu olhar e de sua ação singular no mundo" (BARBIER, 2007, p. 14).

O objeto mais uma vez se redimensiona, não é só uma implicação ao outro, tem que ver com o processo da pesquisadora, quando se coloca, ela mesma como uma professora em formação, reprojetando o objeto da pesquisa para si. Desde modo, segue o autor, os relatórios, resultados, são produzidos e socializados com os participantes, tornando-se um "grupo-sujeito". De forma que cada ação conjunta se torna ação formativa.

Tendo isso como direcionamento, a fim de proporcionar momentos de discussão e interação entre sujeitos e a pesquisadora, houve um processo diagnóstico que perfizeram onze reuniões, nas quais os licenciando puderam expressar e problematizar aquilo que vivenciaram em sala de aula; para posteriormente, construirmos uma proposta de formação para a docência no Ensino Técnico ${ }^{7}$.

\section{SABERES DOCENTES PARA A EPTNM NA VISÃO DOS LICENCIANDOS}

Considerando os Saberes Docentes enquanto tendência formativa para o Ensino Técnico, Moura (2008) elenca os seguintes aspectos como imprescindíveis na construção desses saberes: questões didático-político-pedagógicas, a função social da EPT, o papel do docente, as relações ensinopesquisa e a discussão política.

Tais aspectos efetivam-se mediante quatro espaços: atividades escolares propriamente ditas; interação com o entorno escolar; espaços de (re)inserção laboral; orientação pedagógica e profissional. Cada um destes é importante na futura atuação do professor, no momento de seu

\footnotetext{
${ }^{7}$ O processo diagnóstico construído, a qual é descrita neste artigo, culminou na elaboração e aplicação de um curso de curta duração, que ocorreu no mês de julho de 2015. As ações ocorridas, registros das atividades, relatos dos alunos e materiais utilizados encontram-se no site do curso, possível de ser acessado em www.docencianaept.com.
} 
planejamento, quando este considerar as diversas especificidades, de maneira interdisciplinar. A unidade ensino-pesquisa é bem enfatizada na perspectiva do trabalho individual e coletivo, uma vez que esta permite visualizar o desenvolvimento da autonomia do professor que se forma, na capacidade de aprender a aprender (MOURA, 2008).

Contribuindo com o debate, Barato (2002) traz à tona a histórica dissociação entre teoria e prática alimentada por fatores de valores sociais, econômicos e políticos, no qual à elite, era conferida educação literária, e aos filhos dos trabalhadores comuns, educação voltada para o trabalho braçal. O reflexo dessa visão foi sentido na pretensa separação entre teoria e prática, entre os aspectos propedêuticos e técnicos do saber sistematizado:

A precedência do termo teoria no par teoria \& prática não é gratuita. Apesar de não corresponder historicamente ao modo pelo qual o conhecimento é elaborado no plano individual e social, o citado par acaba orientando decisões didáticas no campo da educação profissional (BARATO, 2002, p. 143).

Barato (2002) preconiza a técnica como um saber, no qual a prática não se sobrepõe à teoria e vice-versa, mas são imbricadas no processo de construção saber técnico, composto pelos seguintes elementos: informação, conhecimento e desempenho. Dessa forma, pensar a formação de professores seria um esforço, primeiramente de revestir epistemologicamente o par teoria e prática, no seu diálogo, evitando o subjugamento de uma em relação à outra.

Um dos caminhos para a não dissociação entre teoria e prática na formação de professores é alocar essas discussões no contexto de atuação profissional de cada professor, pois não há como desvinculá-lo dos aspectos institucionais, os quais são constituintes do seu fazer docente, pois conforme Mancebo (2009, p. 207-208),

[...] por um lado, o docente é configurado como trabalhador de um sistema produtivo, imerso numa nova organização do trabalho; por outro lado, o produto do seu trabalho - "força de trabalho competente" e "tecnologia e conhecimento cientifico" -, fundamental na dinâmica do novo funcionamento sócio produtivo, também é afetado. 
Situar as práticas de formação no contexto de atuação do professor pode proporcionar condições deste fazer uso dos conhecimentos construídos em situações específicas e diversas. Como preconizado por Mancebo (2009, p. 233),

[...] o mais importante é a passagem de um regime no qual predomine um tipo de relação pedagógica (seja ela transmissiva ou construtivista) para um regime em que se articulem diferentes tipos de relação, em razão de demandas próprias de cada contexto, as quais o professor tenha condições teórico-práticas de enfrentar.

Em particular, quando se trata da formação de professores, as relações entre educação e mundo do trabalho convergem para concepções sobre o "tipo" de pessoa que se quer formar e para qual sociedade. Assim, entendemos, a partir de Moura (2008), que é preciso questionar: o que é exigido, dentro de uma determinada concepção de sociedade, homem e educação, ao docente da EPT? Quais os saberes necessários? Partindo desses questionamentos partimos para o entendimento desses saberes na história da EPT. As respostas podem contribuir para novos encaminhamentos e ações que, de fato, contribuam para a formação de professores para esta modalidade de Educação na qual se aloca o Ensino Técnico.

1. Os alunos reconhecem que a docência do Ensino Técnico é diferente de qualquer outro contexto; e isso se demonstra nos objetivos a serem alcançados pelas disciplinas da área de ciências, bem como na escolha da metodologia empregada no processo de ensino; decorrente disso compreendemos que ao professor é demandada a habilidade de lidar com a diversidade, contextualizando os conteúdos de sua disciplina a fim de revesti-la de sentido nos mais diferentes cursos técnicos ${ }^{8}$; nesse processo de significação, a interdisciplinaridade pode mediar o processo de ensino;

2. Nos cursos técnicos do IFAM observou-se que os professores conseguem se utilizar da experimentação, enquanto estratégia metodológica, de maneira mais recorrente. No entanto, isto depende da interação com o curso técnico específico; por exemplo, os licenciandos do curso de química, conseguem promover situações de aprendizagem em laboratório com mais facilidade nos cursos técnicos de Química e Meio Ambiente; os licenciandos de Física, com os cursos técnicos de Eletrotécnica, Edificações e Mecânica; os licenciandos do curso de Biologia, com os cursos técnicos de Química, Meio Ambiente, Edificações e Eletrotécnica. Isso evidencia a possibilidade do licenciando articular teoria e

\footnotetext{
${ }^{8}$ O campus do IFAM no qual a pesquisa está em processo oferta os cursos técnicos de Eletrotécnica, Informática, Edificações, Meio Ambiente, Química e Mecânica, as quais se organizam sob o mesmo projeto pedagógico no Ensino Médio Integrado.
} 
prática, nos cursos técnicos que possuem afinidade à sua área de ensino, embora essa articulação não esteja evidente na sua prática em outros cursos técnicos mais distantes de sua área de formação.

3. Entendem que é relevante conhecer e compreender o contexto institucional no qual seu fazer pedagógico se aloca. Isso implica em alinhar a sua prática aos objetivos da instituição, bem como ao perfil a ser formado nos diferentes cursos técnicos. Isso se mostra importante pelo entendimento dos IFs tendo como braço forte, historicamente a profissionalização.

4. Percebem que entre os alunos do Ensino Médio Integrado há uma tensão entre prepararse para o ensino superior e/ou para uma profissão técnica, o que exige do professor refletir e pensar sua atuação pedagógica e conteúdos de sua disciplina para esse "dilema". Diante desse contexto, evidenciam o diálogo necessário entre as disciplinas de formação geral, com as disciplinas técnicas, embora ainda procurem compreender como isso se daria mediado pelas exigências das avaliações dos alunos (vestibulares e similares); além da formação para o mundo e mercado de trabalho, sem deixar de atender a dimensão formativa integral, conforme preconizado nas diretrizes. Porém, no embate entre o real e o ideal, o que se percebe é uma sobreposição do aspecto da técnica sobre a formação geral.

Os saberes docentes dialogam entre si e fazem sentido ao professor, a partir de sua experiência, sendo seu trabalho realizado por meio da interação (TARDIF, 2014). Da observação participante com os alunos, pudemos identificar algumas inquietações em relação ao Ensino, as quais elencamos a seguir:

É possível perceber que as problematizações lançadas pelos alunos incidem, sobretudo sobre questões do currículo e de conhecimento institucional, a qual possui reflexo direto na sua prática docente no Ensino Técnico, na relação entre Ciência e Trabalho.

\section{CONSIDERAÇÕES FINAIS}

Durante o estudo, buscamos problematizar os saberes necessários à formação de professores para o Ensino Técnico, aproximando-se, a partir dos Saberes Docentes, da historicidade da questão. Compreendemos que este Ensino, estando no âmbito da EPT, revela especificidades, através das quais buscamos elementos que implicam em saberes docentes para o Ensino Técnico. Junto a isso, em um processo de pesquisa-ação, com licenciandos do IFAM que estiveram em contato com a sala de aula, procuramos compreender os saberes docentes a partir de suas vivências.

Decorrente desse processo investigativo percebemos que, neste contexto, alguns aspectos são imprescindíveis ao docente: compreensão da formação humana integral; conhecimento do mundo 
do trabalho, de questões técnicas específicas; compreensão do trabalho como princípio educativo; pesquisa como princípio pedagógico na mediação do ensino e no diálogo com a ciência; a interdisciplinaridade como um dos caminhos para a articulação com as disciplinas gerais e técnicas; o entendimento da relação teoria e prática no contextos dos cursos técnicos; pensar o ensino a partir da realidade da instituição a qual se destina, a fim de seja contextualizado.

Observando a complexidade que se mostra ao professor, e diante da ausência dessa discussão nas formações, julgamos pertinente empreender uma ampliação das investigações referentes a esta formação que abarque as situações acima problematizadas, o que delineamos nos cursos de curta duração construído e realizado com os licenciandos.

\section{AGRADECIMENTOS}

À Fundação de Amparo à Pesquisa do Estado do Amazonas (FAPEAM), pelo apoio para realizar este estudo.

\section{REFERÊNCIAS}

ALMEIDA, P.A.; BIAJONE, J. Saberes docentes e formação inicial de professores: implicações e desafios para as propostas de formação. Educação e Pesquisa, São Paulo, v.33, n.2, p. 281-295, maio/ago. 2007, p. 281-295.

ARANHA, M. L. A. História da educação e da pedagogia: geral e Brasil. 3. ed. São Paulo: Moderna, 2006

BARATO, J. N. Escritos sobre tecnologia educacional e educação profissional. São Paulo: SENAC, 2002.

BAPTAGLIN, L.A. A educação profissional e tecnológica e a aprendizagem da docência: o que está sendo pesquisado nas produções acadêmico-científicas. In: Congresso de Nacional de Educação, 11. Anais... EDUCERE. Curitiba, 2013. Disponível em: <http://educere.bruc.com.br/ANAIS2013/pdf/7518_4366.pdf>. Acesso em: 18 jul. 2014.

BRASIL. Lei n. 11.892, de 29 de dezembro de 2008. Institui a Rede Federal de Educação Profissional, Científica e Tecnológica. Brasília, DF, 2008.

CAPES. Pibid: Programa Institucional de Bolsas de Iniciação à Docência. Disponível em: <http://www.capes.gov.br/educacao-basica/capespibid>. Acesso em: 6 abr. 2015.

CARDOSO, A; DEL PINO, M.A.B; DORNELES, C. L. Os saberes profissionais dos professores na perspectiva de Tardif e Gauhier: contribuições para o campo de pesquisa sobre os saberes docentes no Brasil. Trabalho apresentado ao IX ANPED SUL. Seminário de pesquisa em educação da região sul. Caxias do Sul, 2012.

ESTEBAN, M. P. S. Pesquisa qualitativa em educação: fundamentos e tradições. Porto Alegre: AMGH, 2010.

GARÍGLIO, J. A.; BURNIER. Saberes da docência na educação profissional e Tecnológica: um estudo sobre o olhar dos professores. Educação em Revista, Belo Horizonte. v.28, n.01, p.211-236, mar. 2012.

MANCEBO, D. Tecnologia na Educação: uma questão de tranformação ou de formação. Campinas, SP: Alínea, 2009. 


\section{Silva e Azevedo, 2016 - Formação de professores}

MOURA, D. H. A formação de docentes para a educação profissional e tecnológica. Revista Brasileira da Educação Profissional e Tecnológica. Brasília/MEC/SETC, v.1, n.1, jun. 2008.

PONTES, A. P. F. Professores da Educação Profissional e Tecnológica: alguns aspectos de sua profissionalização e formação. Trabalho apresentado ao VII Congresso Luso-brasileiro de política e administração da educação. Porto, 2014.

SILVA, V. R.; MOURÃO, A. R. B. A Educação Profissional nas Reformas Francisco Campos e Gustavo Capanema. In: MOURÃO, A R B. et al. (Org.). A Educação Profissional na Região Norte: reflexões e críticas. Manaus: EDUA, 2013. p. 15-64.

TARDIF, M. Saberes docentes e formação professional. 16. ed. Petrópolis, RJ: Vozes, 2014.

TRIPP, D. Pesquisa ação: uma introdução metodológica. Educação e Pesquisa, São Paulo, v. 31, n. 3, p. 443-466, set./dez. 2005. 